\title{
THINKING WITH ALGEBRA: A PROJECT AND PERSPECTIVE
}

David Feikes, Professor, Purdue Northwest University, feikesd@pnw.edu

Bir Kafle, Associate Professor, Purdue Northwest University, bkafle@pnw.edu

Natalie McGathey, Associate Professor, Prairie State College, nmcgathey@prairiestate.edu

William S. Walker, Assistant Director of CATALYST, Purdue University, wswalker@purdue.edu

\section{Abstract}

Thinking with Algebra (TWA) is a project to develop algebra curriculum for college classes. The overall goal is to develop curricular materials that will help prepare students conceptually for college algebra. The project is described and the importance of algebraic structure as a theoretical consideration is explained.

\section{Project Description and Theoretical Perspectives}

Thinking with Algebra (TWA) is a project funded by the National Science Foundation (Improving Undergraduate STEM Education: Education and Human Resources program DUE: 202414) to develop an algebra curriculum for college classes. The materials are in development at Purdue University Northwest and Prairie State College. The project's overarching goals are to prepare students conceptually for college algebra and to enhance their overall knowledge of mathematics.

For many mathematics educators, algebra is a beautiful, logical, and abstract mathematics (Usiskin, 1995). Many people become familiar with algebraic problem-solving and do not have to think about all the meanings of algebraic expressions and manipulations. An important question for collegelevel algebra instructors becomes: How do we make the implicit structure of algebra explicit to students? The implicit structure of algebra makes it difficult for novices to understand it in meaningful ways.

One of the aspects that makes algebra unique is its structure. Operations are carried out on algebraic expressions rather than directly with numbers (Kieran, 1992). Furthermore, novice learners are challenged with making meaning out of symbols, expressions, and formulas and seeing the "invisible" objects of algebra is a critical element of mathematical learning and ability (Arcavi et al., 2017, p. 69). "The student should be able to develop a sense of operating on the algebraic expression as a mathematical object in its own right. Such a structural conception involves applying properties not to numbers but to expressions" (Kieran, 1992, p. 397).

As an illustration, consider the following problem: Solve for $r,(2 r+1)^{2}-(2 r+1)=12$. One way to solve this problem is by substituting $\mathrm{x}=2 \mathrm{r}+1$ and then factoring the resulting equation: $\mathrm{x}^{2}-\mathrm{x}=12$. This solution is an example that could be used by someone knowledgeable about the objects and structure of algebra. The expression can be viewed as a quadratic that can be factored. Additionally, the process "multiply the variable by 2 and add 1" can be an object, "x." The object-process duality and moving between the two is one important theoretical aspect of algebra.

The TWA project is investigating the underlying and implicit structure of algebra along with theories of the learning and teaching of algebra to develop a curriculum that promotes conceptual understanding as well as to develop the skills necessary for being successful in algebra. One of the central considerations is making the structural aspects of algebra accessible to all students.

\section{References}

Arcavi, A., Drijvers, P. \& Stacey, K. (2017). The learning and teaching of algebra: Ideas, insights and activities. Routledge.

Kieran, C. (1992). The learning and teaching of school algebra. In D. Grouws, (Ed.), Handbook of research on mathematics teaching and learning (pp. 390-419). NCTM.

Usiskin, Z. (1995): Why is algebra important to learn? In: B. Moses (Ed.), Algebraic thinking in grades K-12: Readings from NCTM's school-based journals and other publications. Reston, VA: NCTM, p. 16-21 